\title{
Diaphragm dysfunction in chronic obstructive pulmonary disease: a role for heparan sulphate?
}

\author{
C.A.C. Ottenheijm*,\#, , ,f, G.J. Jenniskens ${ }^{+, f}$, M.C.P. Geraedts*, T. Hafmans*, \\ L.M.A. Heunks ${ }^{\star \star \#, \S}$, T.H. van Kuppevelt ${ }^{+}$and P.N.R. Dekhuijzen**\#
}

ABSTRACT: In the present study, phage display-derived antibodies were used to investigate the topology of glycosaminoglycan epitopes in the diaphragm of chronic obstructive pulmonary disease (COPD) and non-COPD patients. Furthermore, the potential physiological significance of changes in the occurrence of glycosaminoglycan epitopes in the diaphragm of COPD patients was studied by determining the overlap in epitope recognition of glycosaminoglycan antibodies and growth factors.

Diaphragm cryosections from non-COPD $(n=5)$ and COPD patients (Global Initiative for Chronic Obstructive Lung Disease (GOLD) stage I/II; $n=9$ ) were incubated with antibodies directed against heparan sulphate, chondroitin sulphate and dermatan sulphate epitopes. Antibodies were visualised immunofluorescently. In addition, interference of antibody and growth factor binding with heparan sulphate epitopes was tested.

Specific glycosaminoglycan epitopes showed increased expression in the diaphragm of COPD patients, whereas other epitopes were decreased or unaffected. Interestingly, the anti-heparan sulphate antibody HS4C3, which is directed against a downregulated epitope, interfered with the binding of hepatocyte growth factor. Three patients with the most severe airway obstruction also demonstrated interference of heparan sulphate antibody A04B08 with hepatocyte growth factor binding.

Results indicate changes in glycosaminoglycan composition in the diaphragm of patients with chronic obstructive pulmonary disease. This may affect cellular physiology via alterations in growth factor handling and might be related to reduced levels of contractile protein in the diaphragm of these patients.

KEYWORDS: Chronic obstructive pulmonary disease, diaphragm muscle, glycosaminoglycan, heparan sulphate

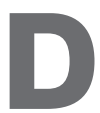
ysfunction of the inspiratory muscles frequently occurs in patients with chronic obstructive pulmonary disease (COPD) [1] and maximum inspiratory pressure is an independent determinant of survival in these patients [2]. Therefore, understanding the underlying mechanisms of inspiratory muscle dysfunction is of major clinical importance.

The diaphragm is the principal inspiratory muscle. Several studies have shown adaptations in diaphragm morphology and function in patients with COPD [3-9]. Recently, it has been shown that these patients have a diminished diaphragmatic myosin content, which compromises force generation early in the course of the disease (Global Initiative for Chronic Obstructive Lung Disease (GOLD) stage I/II) [8]. Contractile protein content is the net result of protein synthesis and degradation. Although the activity of the most important intracellular proteolytic system, i.e. the ubiquitin-proteasome pathway, is increased in the diaphragm of patients with mildto-moderate COPD [10], the possible involvement of mediators that affect the rate of muscle protein synthesis has not yet been investigated.

Glycosaminoglycans are linear unbranched polysaccharides, most of which are covalently linked to a protein core to form proteoglycans [11]. Depending on the nature of the glycosaminoglycan moiety, heparan sulphate, dermatan sulphate and chondroitin sulphate proteoglycans can be discerned. Most proteoglycans are found either on the cell surface (e.g. syndecan and glypican) or in the extracellular matrix (e.g. perlecan and

\section{AFFILIATIONS}

Depts of *Pulmonary Diseases,

${ }^{+}$Matrix Biochemistry and,

${ }^{\S}$ Intensive Care, Nijmegen Centre for Molecular Life Sciences, and,

\#Institute for Fundamental and

Clinical Human Movement Sciences,

Radboud University Nijmegen

Medical Centre, Nijmegen, The Netherlands.

-Dept of Veterinary and Comparative

Anatomy, Pharmacology and

Physiology, Washington State University, Pullman, WA, USA

${ }^{\dagger}$ C.A.C. Ottenheijm and G.J.

Jenniskens contributed equally to the present study.

\section{CORRESPONDENCE}

C.A.C. Ottenheijm

Dept of Pulmonary Diseases

Radboud University Nijmegen

Medical Centre

P.0. Box 9101

6500 HB Nijmegen

The Netherlands

Fax: 31243610324

E-mail: c.ottenheijm@long.umcn.nl

Received:

September 252006

Accepted after revision:

March 162007

STATEMENT OF INTEREST

Statements of interest for all authors of this manuscript can be found at www.erj.ersjournals.com/misc/ statements.shtml 


\begin{tabular}{|c|c|c|}
\hline & Non-COPD & COPD \\
\hline Subjects $n$ & 5 & 9 \\
\hline Male/female & $5 / 0$ & $8 / 1$ \\
\hline Age yrs & $58 \pm 4$ & $60 \pm 3$ \\
\hline BMI $\mathbf{k g} \cdot \mathrm{m}^{-2}$ & $28 \pm 2$ & $25 \pm 2$ \\
\hline FEV $_{1} \%$ pred & $94 \pm 7$ & $75 \pm 6$ \\
\hline VC $\%$ pred & $93 \pm 6$ & $97 \pm 8$ \\
\hline FEV $1 /$ VC \% & $77 \pm 2$ & $59 \pm 2$ \\
\hline TLC \% pred & $93 \pm 3$ & $103 \pm 8$ \\
\hline$D L, C o / V_{A} \%$ pred & $99 \pm 10$ & $82 \pm 6$ \\
\hline $\mathrm{Pa}, \mathrm{O}_{2} \mathrm{kPa}$ & $11.4 \pm 0.5$ & $11.6 \pm 0.3$ \\
\hline $\mathrm{Pa}, \mathrm{CO}_{2} \mathrm{kPa}$ & $5.4 \pm 0.4$ & $5.0 \pm 0.2$ \\
\hline \multicolumn{3}{|c|}{$\begin{array}{l}\text { Data are presented as mean } \pm \text { SEM, unless otherwise stated. COPD: chronic } \\
\text { obstructive pulmonary disease; } \mathrm{BMI} \text { : body mass index; FEV } \text { : forced expiratory } \\
\text { volume in one second; \% pred: \% predicted; } V \mathrm{~V} \text { : vital capacity; TLC: total lung } \\
\text { capacity; } \mathrm{DL}, \mathrm{CO} / \mathrm{VA} \text { : diffusion capacity of the lung for carbon monoxide per unit } \\
\text { of alveolar volume; } \mathrm{Pa}, \mathrm{O}_{2} \text { : arterial oxygen tension; } \mathrm{Pa}_{1} \mathrm{CO}_{2} \text { : carbon dioxide arterial } \\
\text { tension. }\end{array}$} \\
\hline
\end{tabular}

agrin) $[12,13]$. In skeletal muscle, glycosaminoglycans are involved in numerous biological processes, notably the orchestration of anabolic and catabolic signalling by unique sulphation patterns on the heparan sulphate molecule [14]. Heparan sulphate is essential for the activation of: individual members of the fibroblast growth factor family $[15,16]$; hepatocyte growth factor [17]; insulin-like growth factor binding proteins [18]; platelet-derived growth factor [19]; and transforming growth factor- $\beta$ [20]. The dynamic spatiotemporal expression of proteoglycans and heparan sulphate epitopes provides a micro-environment in which heparan sulphate mediates growth factor activity by creating focal differences in concentration and by facilitating ligand-receptor interactions [21]. Through this modulating effect on growth factors, glycosaminoglycans are instrumental in skeletal muscle regeneration [22-24].

Investigating the exact nature of the involvement of glycosaminoglycans in myopathies has been hampered by a lack of appropriate tools. The present authors have previously generated an array of glycosaminoglycan-specific antibodies that can be used to detect potential changes in the topological distribution of glycosaminoglycan epitopes [25]. In the present study, these antibodies have been used to investigate the occurrence of glycosaminoglycan epitopes in the human diaphragm and possible changes in the diaphragm of patients with COPD. Furthermore, the potential physiological significance of changes in the occurrence in COPD of glycosaminoglycan epitopes, particularly heparan sulphate epitopes, was studied by determining the interference of growth factors and antibodies on the binding of heparan sulphate epitopes.

\section{METHODS}

\section{Subjects and pulmonary function testing}

Diaphragm muscle biopsies ( $\sim 150 \mathrm{mg}$ ) from the anterior costal mid-belly region were obtained from nine COPD (eight males)

\begin{tabular}{|c|c|c|c|c|c|}
\hline \multirow{2}{*}{$\begin{array}{l}\text { TABLE } 2 \\
\text { Clone }\end{array}$} & \multicolumn{5}{|c|}{$\begin{array}{l}\text { Characteristics of the glycosaminoglycan } \\
\text { domain-specific antibodies used in the present } \\
\text { study }\end{array}$} \\
\hline & CDR3 & VH & DP & GAG & [Ref.] \\
\hline АО4В08 & SLRMNGWRAHQ & 3 & 47 & $\mathrm{HS}^{\#}$ & 27 \\
\hline $\mathrm{HS} 4 \mathrm{C} 3$ & GRRLKD & 3 & 38 & $\mathrm{HS}^{\circ}$ & 25 \\
\hline IO3H10 & AKRLDW & 1 & 7 & $\mathrm{CS}^{+}$ & 28 \\
\hline IO3H12 & MKTRLDV & 3 & 46 & CS & 28 \\
\hline 104C2 & GKQRYS & 3 & 54 & $\mathrm{CS} / \mathrm{Hep}$ & 28 \\
\hline LKN1 & GIKL & 1 & 25 & $\mathrm{DS}^{\mathrm{s}}$ & 29 \\
\hline \multicolumn{6}{|c|}{ 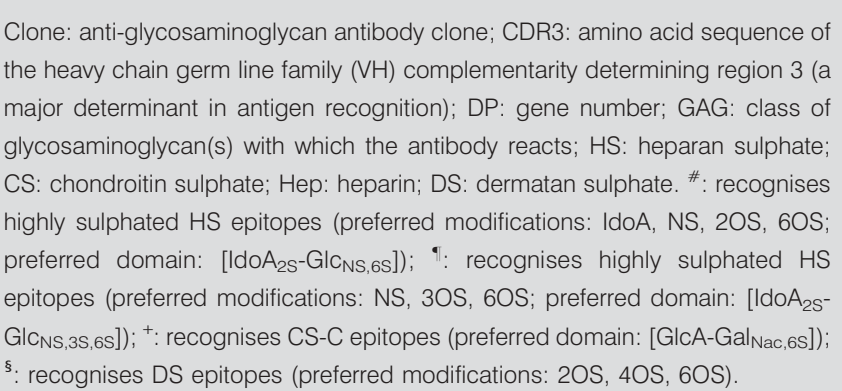 } \\
\hline
\end{tabular}

and five non-COPD (all males) patients during thoracotomy for lung cancer (tumour $1-3$, node $0-1$, metastasis 0 ; equally distributed within groups). Fresh biopsy specimens were rapidly frozen in liquid-nitrogen-cooled isopentane and stored at $-80^{\circ} \mathrm{C}$. Exclusion criteria included: weight loss of $>10 \%$ in the 6 months prior to surgery; prolonged use of corticosteroids; neuromuscular diseases; thyroid diseases; and chronic heart failure. General characteristics and pulmonary function data are shown in table 1 . The study was approved by the local ethics committee and informed consent was obtained prior to surgery.

\section{Phage display-derived anti-glycosaminoglycan antibodies}

Phage display-derived single-chain variable fragment antibodies were obtained as previously described elsewhere [25, 26]. Briefly, antibody-expressing phages were added to glycosaminoglycan-coated tubes, and bound phages were eluted and allowed to infect Escherichia coli cells. After overnight amplification, phages were rescued by addition of helper phage and they were then grown, purified and used for a next round of selection. Following four rounds of selection, individual phages were picked, grown, induced by isopropyl $\beta$-D-1-thiogalactopyranoside, and antibodies were harvested from the periplasmic fraction. Six antibodies were used in the present study: antibodies HS4C3 and AO4B08 against heparan sulphate; IO3H10, IO3H12 and IO4C2 against chondroitin sulphate; and LKN1 against dermatan sulphate (table 2).

\section{Immunofluorescence studies on glycosaminoglycan epitopes}

The occurrence of epitopes recognised by the antibodies was assessed on cryosections by means of immunofluorescence microscopy. Cryosections $(5 \mu \mathrm{m})$ were cut from frozen diaphragm specimens, dried and stored at $-80^{\circ} \mathrm{C}$. Cryosections were rehydrated for $10 \mathrm{~min}$ with PBS, blocked with PBS containing $2 \%$ (weight $(\mathrm{w}) /$ volume $(\mathrm{v})$ ) bovine serum albumin 

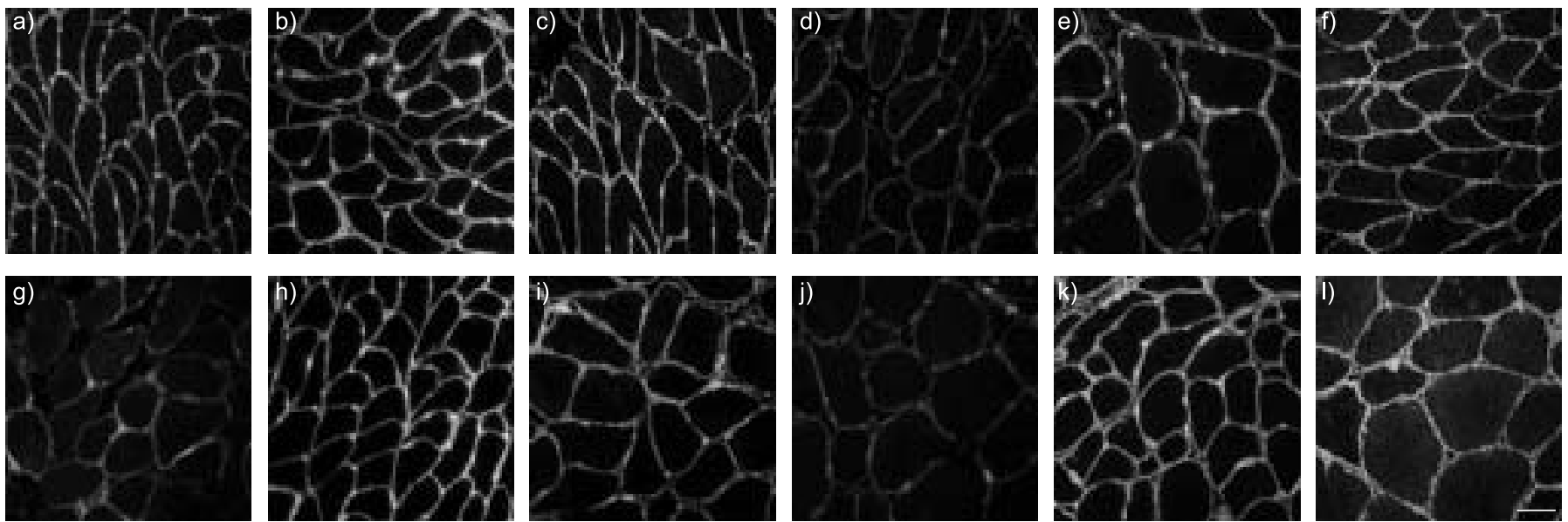

$\mathrm{IO} 3 \mathrm{H} 1 \mathrm{O}$

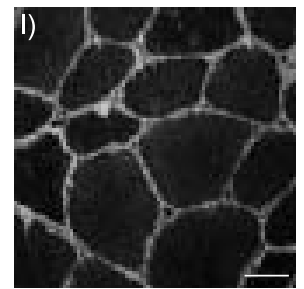

LKN1
$\mathrm{IO} 3 \mathrm{H} 12$

Anti-chondroitin sulphate

Anti-heparan sulphate

Anti-dermatan sulphate

FIGURE 1. Staining of diaphragm cryosections from patients with $(g-l)$ and without $(a-f)$ chronic obstructive pulmonary disease (COPD) with different antiglycosaminoglycan antibodies. Cryosections were incubated with anti-heparan sulphate antibodies HS4C3 (a and g) and AO4B08 (b and h); anti-chondroitin sulphate antibodies $103 \mathrm{H} 10$ ( $\mathrm{c}$ and i), IO3H12 ( $\mathrm{d}$ and j) and IO4C2 (e and k); and anti-dermatan sulphate antibody LKN1 (f and I). Bound antibodies were visualised using anti-vesicular stomatitis virus antibody P5D4 followed by a Alexa 488-conjugated goat anti-mouse antibody. The staining intensity of the epitope recognised by HS4C3 is decreased in COPD patients (g), whereas the staining intensity of the epitope recognised by $104 \mathrm{C} 2$ is increased in these patients $(\mathrm{k})$. The staining intensity of epitopes recognised by antibodies AO4B08, IO3H10, IO3H12 and LKN1 is similar in COPD and non-COPD patients. Scale bar $=25 \mu \mathrm{m}$.

(BSA) for $10 \mathrm{~min}$ and incubated with anti-glycosaminoglycan antibodies for $60 \mathrm{~min}$. Bound antibodies were detected with mouse anti-vesicular stomatitis virus monoclonal antibody

\begin{tabular}{|c|c|c|c|c|c|c|}
\hline TABLE 3 & $\begin{array}{l}\text { Immunos } \\
\text { glycosam }\end{array}$ & $\begin{array}{l}\text { taining it } \\
\text { hinoglyce }\end{array}$ & $\begin{array}{l}\text { ntensity } \\
\text { an antib }\end{array}$ & $\begin{array}{l}\text { of anti- } \\
\text { dies }\end{array}$ & & \\
\hline Patient & HS4C3 & АО4B08 & IO3H10 & 103H12 & IO4C2 & LKN1 \\
\hline \multicolumn{7}{|l|}{ Non-COPD } \\
\hline 1 & ++ & ++ & ++ & + & + & + \\
\hline 2 & ++ & + & ++ & $+/-$ & $-1+$ & ++ \\
\hline 3 & ++ & ++ & $++/+$ & $+/-$ & $+/-$ & ++ \\
\hline 4 & ++ & ++ & ++ & + & $++/+$ & ++ \\
\hline 5 & + & ++ & ++ & $+/-$ & $+/-$ & + \\
\hline \multicolumn{7}{|l|}{ COPD } \\
\hline 6 & + & ++ & ++ & + & ++ & + \\
\hline 7 & $+/-$ & ++ & ++ & $+/-$ & $++/+$ & ++ \\
\hline 8 & $++/-$ & + & ++ & $+/-$ & ++ & ++ \\
\hline 9 & $+/-$ & + & ++ & + & $++/-$ & + \\
\hline 10 & $++/+$ & ++ & ++ & + & + & ++ \\
\hline 11 & $-/+$ & ++ & ++ & $+/-$ & $++/+$ & + \\
\hline 12 & $+/-$ & ++ & + & + & $++/+$ & ++ \\
\hline 13 & $+/-$ & $++/+$ & ++ & + & + & $++/-$ \\
\hline 14 & $+/-$ & + & ++ & $+/-$ & + & + \\
\hline
\end{tabular}

COPD: chronic obstructive pyulmonary disease. Cryosections of human diaphragm were incubated with anti-glycosaminoglycan antibodies. Bound antibodies were visualised by incubation with fluorescently labelled antibodies. ++: very strong staining intensity; +: strong; -: negative. Staining intensity of cryosections displaying intensity differences between areas were scored as follows: +/-: strong with negative areas; ++/-: very strong with negative areas; $++/+$ : very strong with strong areas; -/+: negative with positive areas
(P5D4), followed by incubation with Alexa 488-conjugated goat anti-mouse immunoglobulin G (60 min each). Cryosections were washed three times with PBS after each incubation. Finally, the cryosections were fixed in $100 \%$ ethanol, dried and embedded in Mowiol (10\% (w/v) in $0.1 \mathrm{M}$ Tris, $\mathrm{pH} 8.5 / 25 \%$ $(\mathrm{v} / \mathrm{v})$ glycerol $/ 2.5 \%(\mathrm{w} / \mathrm{v})$ sodium azide).

To evaluate the specificity of the antibodies, diaphragm cryosections were pre-incubated overnight at $30^{\circ} \mathrm{C}$ with heparinase-I/III to digest heparan sulphate (0.02 international unit (IU) $\cdot \mathrm{mL}^{-1}$ each in $50 \mathrm{mM}$ sodium acetate $/ 5 \mathrm{mM}$ calcium acetate, $\mathrm{pH}$ 7.0) and with chondroitinase-avidin biotinylated complex $(\mathrm{ABC})$ to digest chondroitin sulphate/dermatan sulphate (0.02 IU. $\mathrm{mL}^{-1}$ in $25 \mathrm{~mL}$ Tris-hydrochloride, $\mathrm{pH}$ 8.0). As a control, cryosections were incubated in the reaction buffer without enzyme. After washing with PBS and blocking with $\mathrm{PBS} / 2 \%(\mathrm{w} / \mathrm{v}$ ) BSA, cryosections were incubated with heparan sulphate or chondroitin sulphate antibodies and processed for immunofluorescence as described previously. The efficiency of enzymatic treatment was evaluated by incubation with antibodies against glycosaminoglycan "stubs". For heparan sulphate stubs, antibody 3G10 was used. For chondroitin sulphate stubs, antibody 2B6 was used (both from Seikagaku, Tokyo, Japan).

Optimal concentrations for primary antibodies were determined in titration series on rat peripheral soleus muscle. All stainings in the present study were performed using the conditions that yield maximal staining at minimal antibody concentration. Series of non-COPD and COPD cryosections were incubated in parallel (using the same solutions) and analysed by two independent observers. Intensity scores were rated for entire cryosections (at $\times 200$ magnification; average cryosection $0.20 \mathrm{~cm}^{2}$ ) by comparison with the maximum 

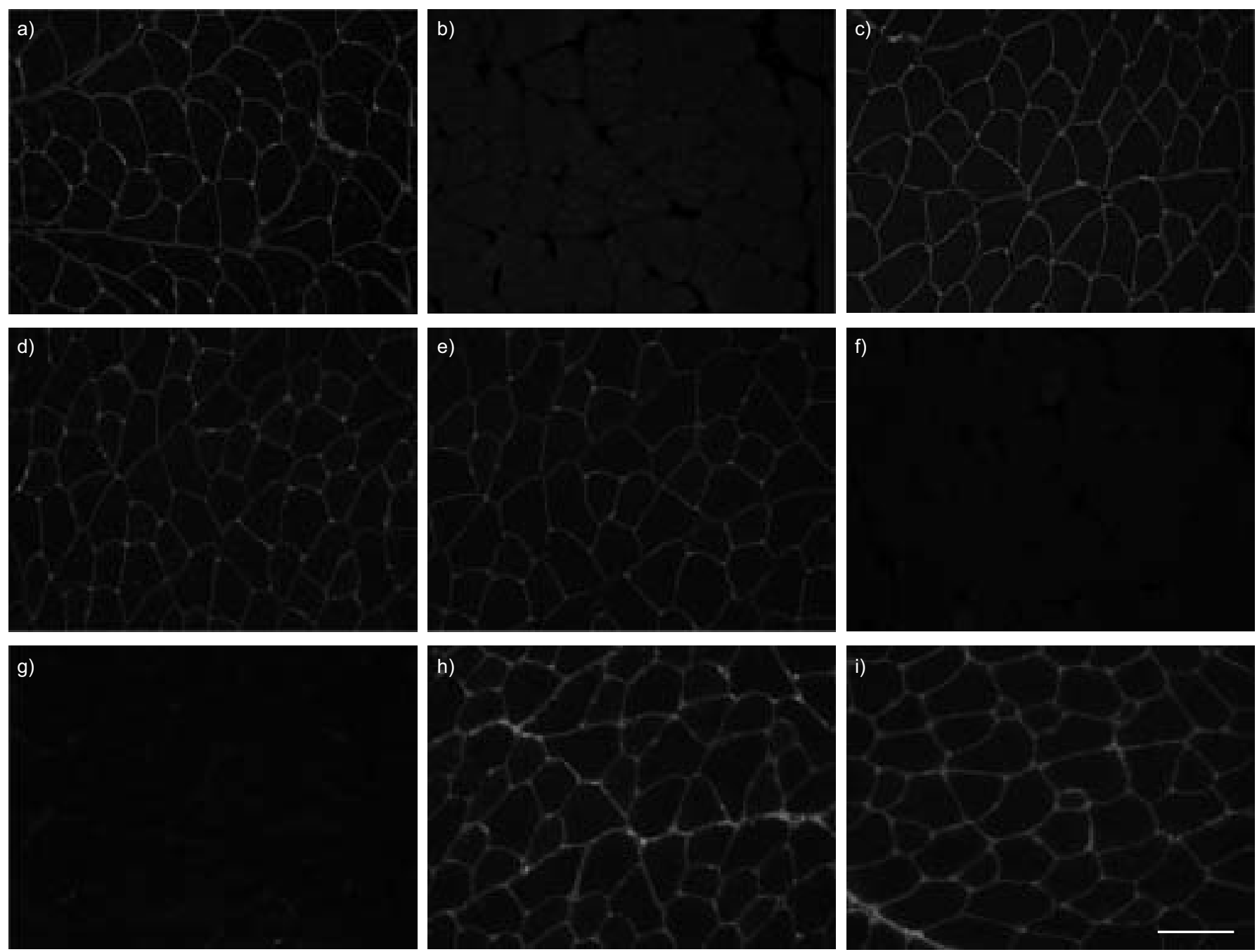

Control

Heparinase-I/II

Chondroitinase-AC

FIGURE 2. Staining of heparinase-I/III and chondroitinase-AC treated rat soleus muscle cryosections. Non-treated (a, $d$ and g), heparinase-I/III treated (b, e and $h$ ) and chondroitinase-AC treated ( $\mathrm{c}, \mathrm{f}$ and i) cryosections were incubated without primary antibody ( $\mathrm{g}$ ), with anti-heparan sulphate antibody HS4C3 (a-c), anti-chondroitin sulphate antibody 104C12 (d-f), anti-heparan sulphate stub 3G10 (h) or anti-chondroitin sulphate stub 2B6 (i). Bound antibodies were visualised using a rabbit anti-vesicular stomatitis virus antibody, followed by Alexa 488-conjugated goat anti-rabbit (a-g), or using Alexa 488-conjugated goat anti-mouse antibody ( $\mathrm{h}$ and $\mathrm{i}$; control experiment omitting the primary antibody was blank (not shown)). Anti-glycosaminoglycan antibodies stain the muscle endo- and perimysium and capillary endothelium (a and d) and this staining disappears upon enzymatic depolymerisation of the glycosaminoglycan chains in question (b and f), not when the reciprocal glycosaminoglycan is digested (c and e) Staining of heparan sulphate- and chondroitin sulphate-stubs confirms the depolymerisation of these glycosaminoglycans ( $h$ and i). Scale bar=50 $\mu \mathrm{m}$.

staining observed in control tissue as follows. ++: very strong; +: strong; +/-: strong with negative areas; ++/-: very strong with negative areas; $++/+$ : very strong with strong areas; -: negative; -/+: negative with positive areas. The intensity scores of the two independent observers showed a very high level of agreement. Photographs were taken on a Zeiss Axioskop (Carl Zeiss BV, Sliedrecht, the Netherlands) equipped with a Nikon DXM1200 digital camera (Nikon Instruments Europe BV, Badhoevedorp, the Netherlands) with ACT1 software (using similar exposure settings).

To investigate the expression of proteoglycan core proteins, diaphragm cryosections from COPD and non-COPD patients were incubated with antibodies against perlecan (clone 7B5, 1:100 dilution in PBS/2\% (w/v) BSA; Zymed, San Francisco,
CA, USA) and decorin (clone 6B6, 1:500 dilution in PBS-B; Seikagaku). Bound antibodies were visualised as described previously. As a control, primary antibodies were omitted.

\section{Involvement of heparan sulphate epitopes in growth factor binding}

To investigate the presence and localisation of growth factors, diaphragm cryosections from COPD and non-COPD patients were incubated with antibodies against insulin-like growth factor (IGF)-1 and hepatocyte growth factor (HGF) (SigmaAldrich, Zwijndrecht, the Netherlands). The antibodies were visualised as described previously. The specificity of the antiIGF-1 antibody was demonstrated by gradually reduced antibody staining after pre-incubating diaphragm crysections with increasing concentrations of human IGF-1 (data not 

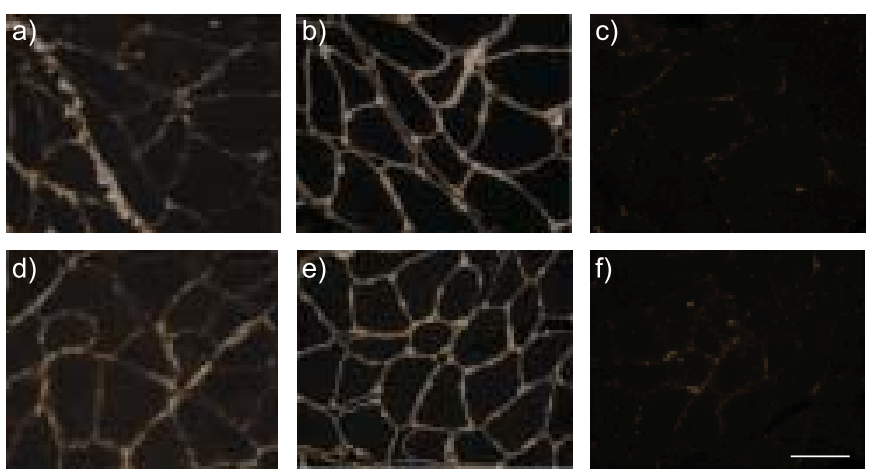

FIGURE 3. Staining of diaphragm cryosections from chronic obstructive pulmonary disease (COPD; $d-f$ ) and non-COPD $(a-c)$ patients for proteoglycan core proteins. Cryosections were incubated with antibodies against decorin (a and d) or perlecan ( $b$ and e). Bound antibodies were visualised using an Alexa 488conjugated goat anti-mouse antibody. As a control, primary antibodies were omitted (c and f). The staining intensity of both decorin (a chondroitin sulphate/ dermatan sulphate proteoglycan present throughout the extracellular matrix) and perlecan (an extracellular matrix heparan sulphate proteoglycan present proximal to the sarcolemma) are similar in COPD and non-COPD patients. Scale bar $=50 \mu \mathrm{m}$.

shown). Similar results were found for the anti-HGF antibody using human HGF.

To investigate whether the glycosaminoglycan epitopes are involved in the binding of growth factors, the present authors studied the possible interference between growth factor and antibody binding to heparan sulphate epitopes as previously described elsewhere [30]. Briefly, IGF-1 or HGF were added to diaphragm cryosections at a concentration of $10 \mu \mathrm{g} \cdot \mathrm{mL}^{-1}$ in PBS $/ 0.1 \%$ BSA and allowed to bind endogenous heparan sulphate epitopes. The cryosections were then washed and anti-heparan sulphate antibodies were allowed to bind, and both growth factor and antibodies were visualised. Alternatively, anti-heparan sulphate antibodies were preincubated on cryosections followed by incubation with the growth factors. Both heparan sulphate epitopes and growth factors were visualised as described previously. The present authors evaluated whether staining intensity was reduced upon pre-incubation with either anti-heparan sulphate antibodies or growth factors. Results were analysed by two independent observers.

\section{RESULTS}

\section{Subject characteristics}

Patient characteristics and pulmonary function data are shown in table 1. COPD patients were classified as having mild or moderate COPD according to GOLD classification [31, 32].

\section{Immunofluorescence studies on glycosaminoglycan epitopes}

All anti-glycosaminoglycan antibodies stained the endo- and perimysium in diaphragm cryosections from non-COPD patients. Overall staining intensity of the antibodies ranged from very strong without negative areas (HS4C3, AO4B08, IO3H10 and LKN1) to moderate with negative areas (IO3H12 and IO4C2; fig. 1). All antibodies stained the extracellular matrix of the endothelial layer of blood vessels.

In COPD patients, the anti-heparan sulphate antibody HS4C3 stained less intensely when compared with non-COPD patients (figs $1 \mathrm{a}$ and $1 \mathrm{~g}$, table 3 ). Patients with COPD had negative areas, whereas this was not observed in non-COPD patients. In contrast to heparan sulphate epitope HS4C3, the anti-chondroitin sulphate antibody $\mathrm{IO} 4 \mathrm{C} 2$ appeared to stain more intensely with less negative areas in patients with COPD. AO4B08, IO3H10, IO3H12 and LKN1 immunofluorescence was not different between groups.

Treatment of cryosections with heparinase-I/III and chondroitinase-ABC completely abolished staining of anti-heparan and anti-chondroitin sulphate antibodies, respectively (fig. 2). Positive staining of heparan sulphate- and chondroitin sulphatestubs indicates the efficiency of the enzymatic treatment.

The representative micrographs shown in figure 3 illustrate that the staining intensity of both decorin (a chondroitin sulphate/dermatan sulphate proteoglycan present throughout the extracellular matrix) and perlecan (an extracellular matrix heparan sulphate proteoglycan present proximal to the sarcolemma) are similar in COPD and non-COPD patients.

\section{Involvement of heparan sulphate epitopes in growth factor binding}

To investigate the localisation of endogenous growth factors, cryosections were incubated with anti-growth factor antibodies. In non-COPD patients, strong staining of endogenous IGF-1 was observed in the cytoplasm of specific fibres (fig. 4a). These fibres were identified as type-I fibres by myosin heavy chain isoform typing (fig. 4e-h). In contrast, endogenous HGF was only faintly detectable in the endomysium (fig. 4b). Patients with COPD showed a strongly decreased staining of IGF-1 when compared with non-COPD patients, whereas staining of HGF was increased in the endomysium.

To investigate whether the antibody-defined heparan sulphate epitopes co-localise with growth factor binding sites, inhibition studies were performed on cryosections from both COPD and non-COPD patients. Pre-incubation with anti-heparan sulphate antibody HS4C3 decreased the binding of HGF (fig. 5; table 4) but not of IGF-1. Pre-incubation with anti-heparan sulphate antibody AO4B08 did not affect binding of IGF-1. In contrast to HS4C3, pre-incubation with $\mathrm{AO} 4 \mathrm{O} 8$ did not affect binding of HGF, except in three patients with COPD (patients 11,12 and 14). In a reciprocal inhibition experiment, the present authors investigated the effect of pre-incubation with exogenous growth factors on subsequent binding of HS4C3 and AO4B08. Pre-incubation with HGF inhibited binding of HS4C3 (fig. 5; table 5), whereas pre-incubation with IGF-1 partially inhibited binding of HS4C3 (table 5). Binding of AO4B08 was not inhibited by pre-incubation with either of the growth factors.

\section{DISCUSSION}

The present study is the first to investigate the topology of glycosaminoglycan epitopes in human diaphragm muscle, particularly in patients with COPD. The current results indicate the downregulation of a specific heparan sulphate epitope, encoded by antibody HS4C3, in the diaphragm of 

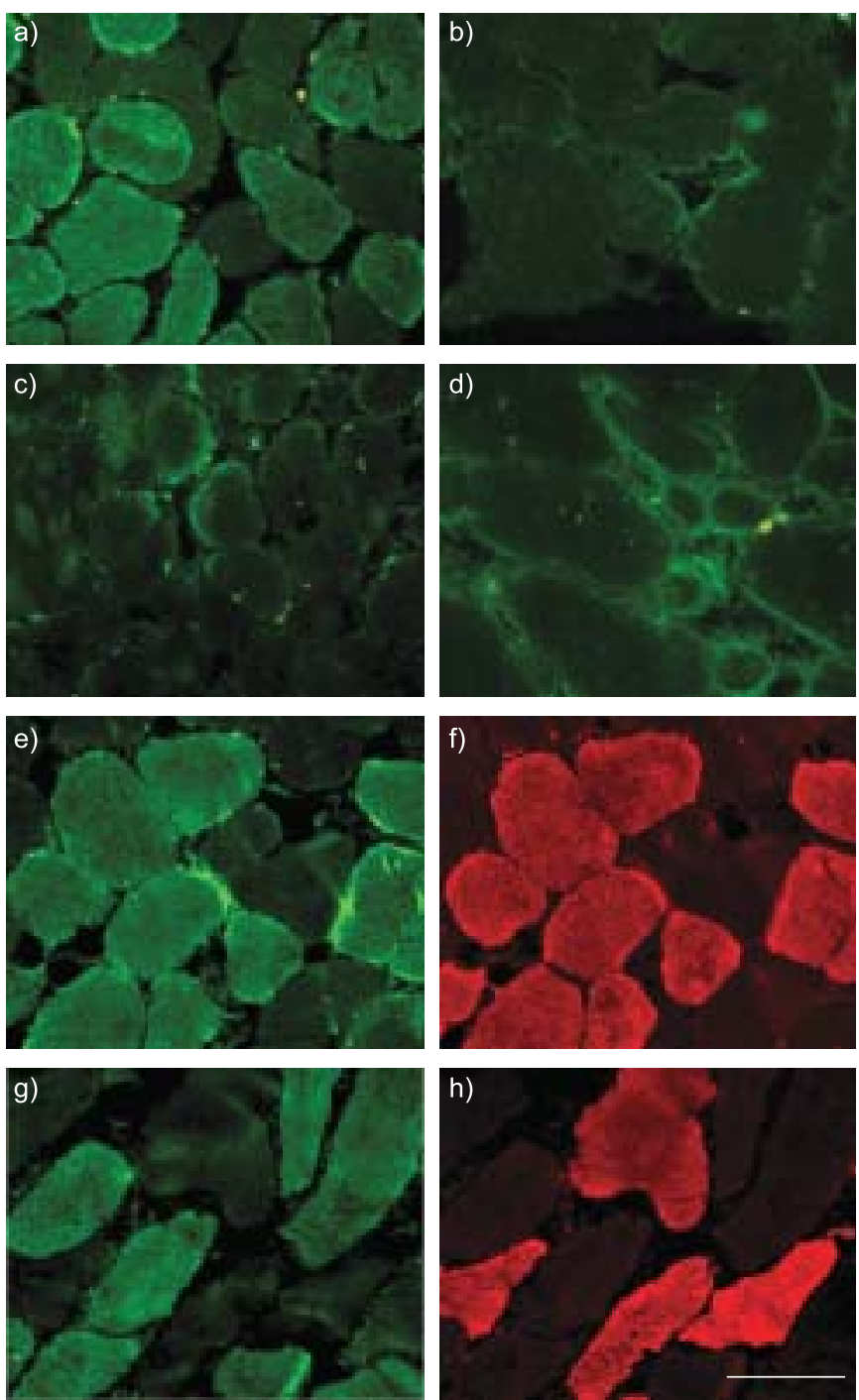

FIGURE 4. Localisation of endogenous insulin-like growth factor (IGF)-1 (a and c) and hepatocyte growth factor (HGF; b and d) in diaphragm from non-chronic obstructive pulmonary disease (non-COPD; $a$ and b) and COPD patients ( $c$ and d). Diaphragm cryosections were incubated with anti-growth factor antibodies. Bound antibodies were visualised using anti-vesicular stomatitis virus antibody P5D4, followed by Alexa 488-conjugated goat anti-mouse antibody. Endogenous IGF-1 shows strong cytoplasmic staining of type-l fibres in non-COPD patients (a), but only little staining in patients with COPD (c). Compared with non-COPD patients (b), patients with COPD show an increased staining of endogenous HGF in the endomysium (d). e-h) Double-staining of non-COPD diaphragm with anti-IGF-1 (e and g) and with anti-myosin heavy chain type-I (f) or -II (h). IGF-1 staining in diaphragm fibres was present predominantly in type-l fibres. Scale bar $=50 \mu \mathrm{m}$.

COPD patients. Interestingly, this downregulated heparan sulphate epitope appears to be involved in the binding of HGF. As HGF is an important modulator of contractile protein synthesis [33], the observed downregulation of this heparan sulphate epitope may affect contractile protein content in the diaphragm of COPD patients. Interestingly, these changes already occur in patients with mild-to-moderate COPD (GOLD stage I/II).

\section{Decreased expression of heparan sulphate epitopes in COPD diaphragm}

The heparan sulphate epitopes studied presently are located in the endo- and perimysium of diaphragm muscle fibres (fig. 1). A decreased staining of anti-heparan sulphate antibody HS4C3 was observed in COPD patients, whereas staining of the antiheparan sulphate antibody AO4B08 was not different between both groups. These findings suggest decreased expression of specific heparan sulphate epitopes in the diaphragm of COPD patients, whereas other epitopes appear to be preserved. Figure 3 suggests that the decreased expression of this heparan sulphate epitope is not merely a reflection of decreased expression of extracellular matrix heparan sulphate proteoglycans present proximal to the sarcolemma [14], as perlecan expression appears comparable between both groups.

\section{Preference for growth factor binding of the downregulated heparan sulphate epitopes}

Heparan sulphates are required for successful muscle regeneration after injury [24] through binding and modulating the activity of proteins [34, 35], particularly growth factors [14]. The growth factors HGF and IGF-1 are major regulators in muscle regeneration, as they stimulate quiescent satellite cells upon fibre injury and the subsequent expression of contractile proteins [33, 36, 37]. The diaphragm of COPD patients is characterised by an elevated disruption of sarcomeric proteins [5] and an increased proteolytic activity [10]. In general, muscle injury is followed by an inflammatory response and subsequent regeneration. Despite clear proof of injury, no evidence of increased numbers of inflammatory cells has been reported in the diaphragm of COPD patients [5, 38]. NGUYEN et al. [39] reported lower expression levels of embryonic/neonatal myosin heavy chains in the diaphragm from COPD patients as compared with non-COPD patients. These findings are suggestive of an impaired regenerative response to injury in the diaphragm of COPD patients. A decreased binding capacity for growth factors due to the decreased expression of specific heparan sulphate epitopes could negatively affect muscle protein synthesis and regeneration and, therefore, contribute to the loss of contractile protein $[8,9]$ in the diaphragm of COPD patients.

To determine growth factor binding to the heparan sulphate epitopes, the possible interference of HGF and IGF-1 binding with antibodies specific for the heparan sulphate epitopes was investigated. A diminished staining for HGF was observed after pre-incubation with HS4C3. Similarly, pre-incubation with HGF reduced staining of HS4C3. Thus, HGF and antibody HS4C3 appear to compete for binding to similar heparan sulphate modifications. Pre-incubation with HS4C3 did not interfere with the binding of IGF-1. However, preincubation with IGF-1 and subsequent incubation with HS4C3 reduced HS4C3 staining. Therefore, IGF-1 might bind to heparan sulphate modifications overlapping with or nearby the HS4C3 epitope.

In contrast to HS4C3, antibody AO4B08 did not interfere with the binding of HGF, except for in three COPD patients (patients 11, 12 and 14; tables 4 and 5). Interestingly, these three patients had the most severe COPD of the patients studied (FEV1 $58 \pm 2$ versus $83 \pm 7 \%$ predicted). It could be 

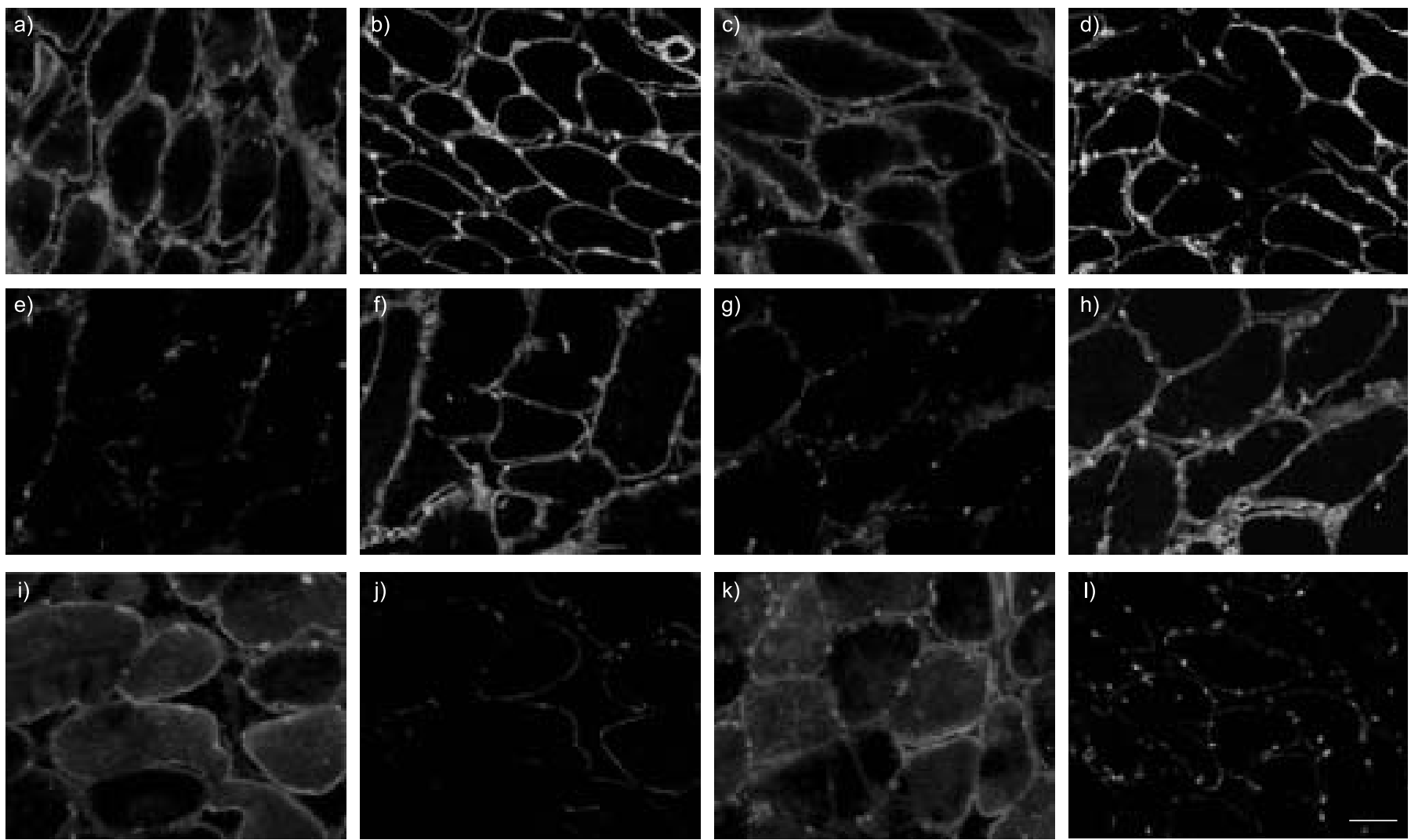

HGF

$\mathrm{HS} 4 \mathrm{C} 3$

HGF

HS4C3

NonCOPD

COPD

FIGURE 5. Interference of heparan sulphate binding by hepatocyte growth factor (HGF) and HS4C3 in chronic obstructive pulmonary disease (COPD; c, d, g, h, k and I) and non-COPD ( $a, b, e, f, i$ and j) patients. Incubation with only HGF (a and c) shows strong staining of the endomysium in diaphragm cryosections from non-COPD and COPD patients. Incubation with only HS4C3 shows strong staining of the endomysium (b and d). Cryosections from non-COPD and COPD patients were either pre-incubated with HS4C3 (e-h) followed by incubation with HGF or pre-incubated with HGF (i-l) followed by incubation with HS4C3. Bound HS4C3 and HGF were visualised by doublestaining. Following pre-incubation with HS4C3 ( $f$ and $h$ ) cryosections show no staining of HGF (e and g). Similarly, when pre-incubated with HGF ( $\mathrm{i}$ and k) cryosections show no staining of HS4C3 (j and I). Scale bar $=25 \mu \mathrm{m}$.

hypothesised that the loss of HS4C3 epitopes in the diaphragm of COPD patients is maladaptive by reducing the capacity to bind growth factors and, with the progression of COPD, this effect might be compensated by enhanced growth factor binding to other heparan sulphate epitopes, possibly the AO4B08 epitope. It should be noted that the diaphragm cryosections were incubated with supra-physiological growth factor concentrations to assure maximal heparan sulphate epitope binding and competition with the heparan sulphate antibodies. Therefore, caution is warranted when extrapolating these findings to physiological conditions.

\section{Growth factor presence in COPD diaphragm}

The present study is the first to investigate the presence of growth factors in the diaphragm of COPD patients, although this was not the primary focus. The decreased staining of IGF-1 suggests reduced presence of this growth factor in the diaphragm of COPD patients. This reduced growth factor presence could lead to a diminished level of protein synthesis and might be related to the decreased contractile protein content in the diaphragm of these patients $[8,9]$. Remarkably, the IGF-1 staining in the diaphragm of non-COPD patients was present predominantly in fibres expressing the myosin heavy chain 1 isoform (fig. 4e-h). Previous studies in rat diaphragm did not find this fibre-type-dependent IGF staining [40]. Future studies should address the physiological significance of the observed fibre-type-dependent IGF staining.

In contrast to IGF-1, the presence of HGF appears to be increased in the diaphragm of COPD patients. This might be considered to be contradictory to the downregulation of the HGF-binding heparan sulphate epitope encoded by HS4C3. It is possible that the diaphragm increases the local concentration of HGF to counterbalance the reduction of certain heparan sulphate epitopes. Thus, it is hypothesised that in the diaphragm there is a dynamic interaction between growth factors and heparan sulphate epitopes which may be altered in COPD.

\section{Increased expression of a chondroitin sulphate epitope}

The three chondroitin sulphate epitopes studied presently are also located in the endo- and perimysium of diaphragm 


\begin{tabular}{|c|c|c|c|c|}
\hline TABL & $\begin{array}{l}\text { Inhibiti } \\
\text { incuba } \\
\text { HS4C3 }\end{array}$ & $\begin{array}{l}\text { owth fa } \\
\text { anti-he } \\
\text { tB08 }\end{array}$ & $\begin{array}{l}\text { or binding } \\
\text { aran sulp }\end{array}$ & tibodies \\
\hline \multirow[t]{2}{*}{ Patient } & \multicolumn{2}{|c|}{ Pre-incubation with $\mathrm{HS} 4 \mathrm{C} 3$} & \multicolumn{2}{|c|}{ Pre-incubation with AO4B0\& } \\
\hline & IGF-1 & HGF & IGF-1 & HGF \\
\hline \multicolumn{5}{|c|}{ Non-COPD } \\
\hline 1 & + & - & + & + \\
\hline 2 & + & - & + & + \\
\hline 3 & + & - & + & + \\
\hline 4 & + & - & + & + \\
\hline 5 & + & - & + & + \\
\hline \multicolumn{5}{|l|}{ COPD } \\
\hline 6 & + & - & + & + \\
\hline 7 & + & - & + & + \\
\hline 8 & + & - & + & + \\
\hline 9 & + & - & + & + \\
\hline 10 & + & - & + & + \\
\hline 11 & + & - & + & - \\
\hline 12 & + & - & + & + \\
\hline 13 & + & + & + & - \\
\hline 14 & + & - & + & - \\
\hline
\end{tabular}

IGF: insulin-like growth factor; HGF: hepatocyte growth factor; COPD: chronic obstructive pulmonary disease. Cryosections were pre-incubated with $\mathrm{HS} 4 \mathrm{C} 3$ or AO4B08, followed by incubation with growth factors IGF-1 or HGF. Bound antibodies were visualised. An overall inhibition of HGF binding is seen after pre-incubation with $\mathrm{HS} 4 \mathrm{C} 3$, as indicated by the negative HGF-staining. Preincubation of HS4C3 had no effect on the binding of IGF-1. Antibody AO4B08 had no effect on the binding of growth factors IGF-1 and HGF, except in patients 11,12 and 14 (HGF). +: comparable intensity to non-pre-incubated cryosections; -: completely absent staining.

muscle fibres (fig. 1). The staining intensity of one of these chondroitin sulphate epitopes, encoded by IO4C2, is increased in COPD patients (fig. 1e versus $1 \mathrm{k}$; table 3 ). Interestingly, chondroitin sulphate proteoglycans are upregulated in muscle fibres of patients with Duchenne muscular dystrophy and in regenerating muscle fibres in calpainopathy [41]. However, the expression of decorin, a chondroitin sulphate/dermatan sulphate proteoglycan present throughout the extracellular matrix [14], appeared not to be elevated in the diaphragm of COPD patients (fig. 3). This suggests that changes in the expression of the chondroitin sulphate epitope encoded by IO4C2 does not necessarily arise from alternate expression of proteoglycan core proteins, but might reflect changes in the distribution of glycosaminoglycan epitopes. Future studies should establish if, and how, the upregulated chondroitin sulphate epitope affects the regenerative capacity of the diaphragm in COPD.

\section{Therapeutic implications: a role for glycosaminoglycan mimetics?}

Recently, it has been shown that glycosaminoglycan mimetics, synthetic derivatives of dextran, stimulate myogenesis while changing the natural glycosaminoglycan composition, notably

\begin{tabular}{|c|c|c|c|c|}
\hline \multirow{3}{*}{$\begin{array}{l}\text { TABLE } \\
\text { Patient }\end{array}$} & \multicolumn{4}{|c|}{$\begin{array}{l}\text { Inhibition of anti-heparan sulphate antibody } \\
\text { binding by pre-incubation with growth factors }\end{array}$} \\
\hline & \multicolumn{2}{|c|}{ Pre-incubation with IGF-1 } & \multicolumn{2}{|c|}{ Pre-incubation with HGF } \\
\hline & HS4C3 & АО4В08 & HS4C3 & АО4В08 \\
\hline \multicolumn{5}{|c|}{ Non-COPD } \\
\hline 1 & $+/-$ & + & $+/-$ & + \\
\hline 2 & $+/-$ & + & - & + \\
\hline 3 & $+/-$ & + & - & + \\
\hline 4 & $+/-$ & + & $+/-$ & + \\
\hline 5 & $+/-$ & + & - & + \\
\hline \multicolumn{5}{|l|}{ COPD } \\
\hline 6 & $+/-$ & + & + +- & + \\
\hline 7 & + & + & - & + \\
\hline 8 & $+/-$ & + & $+/-$ & + \\
\hline 9 & $+/-$ & + & - & + \\
\hline 10 & $+/-$ & + & - & + \\
\hline 11 & + & + & - & + \\
\hline 12 & + & + & - & + \\
\hline 13 & + & + & - & + \\
\hline 14 & + & + & - & + \\
\hline
\end{tabular}

IGF: insulin-like growth factor; HGF: hepatocyte growth factor; COPD: chronic obstructive pulmonary disease. Cryosections were pre-incubated with growth factors IGF-1 or HGF, followed by incubation with HS4C3 or AO4B08. Bound antibodies were visualised. An overall inhibition was seen for $\mathrm{HS} 4 \mathrm{C} 3$ after preincubation with HGF. After pre-incubation with IGF-1, HS4C3 was slightly inhibited but $\mathrm{AO} 4 \mathrm{~B} 08$ was not. +: comparable intensity to non-pre-incubated cryosections; +/-: reduced intensity compared with non-pre-incubated cryosections; -: completely absent staining.

heparan sulphate [42]. These glycosaminoglycan mimetics stimulate the regeneration of denervated and crushed skeletal muscles [43, 44], as well as prevent most of the damage resulting from acute skeletal or cardiac muscle ischaemia [45]. Therefore, these dextran polymers were called regenerating agents (RGTA). The present authors anticipate the potential therapeutic application of glycosaminoglycans or glycosaminoglycan mimetics in counteracting diaphragm dysfunction in COPD.

\section{Conclusion}

The present study shows that specific glycosaminoglycan epitopes are altered in the diaphragm of patients with chronic obstructive pulmonary disease. Since these epitopes might be involved in growth factor binding, the functional loss of heparan sulphate may negatively affect the anabolic-catabolic balance and, therefore, might be related to the reduced levels of contractile protein in the diaphragm of these patients [8].

\section{ACKNOWLEDGEMENTS}

The present authors would like to thank P.H.K. Jap for his expertise in the field of muscle histology and E. van de Bogaard (both from Radboud University Nijmegen Medical Centre, Nijmegen, the Netherlands) for supporting experiments. The authors are also indebted for collecting the 
diaphragm muscle biopsies to A. Verhagen (Radboud University Nijmegen Medical Centre); F. van den Elshout, S. van Sterkenburg, W. de Vries, T. Bloemen (Rijnstate Hospital, Arnhem, the Netherlands); and F. Smeenk and B. van Straten (Catharina Hospital, Eindhoven, the Netherlands).

\section{REFERENCES}

1 Laghi F, Tobin MJ. Disorders of the respiratory muscles. Am I Respir Crit Care Med 2003; 168: 10-48.

2 Gray-Donald K, Gibbons L, Shapiro SH, Macklem PT, Martin JG. Nutritional status and mortality in chronic obstructive pulmonary disease. Am J Respir Crit Care Med 1996; 153: 961-966.

3 Levine S, Kaiser L, Leferovich J, Tikunov B. Cellular adaptations in the diaphragm in chronic obstructive pulmonary disease. $N$ Engl J Med 1997; 337: 1799-1806.

4 Levine S, Nguyen T, Kaiser LR, et al. Human diaphragm remodeling associated with chronic obstructive pulmonary disease: clinical implications. Am J Respir Crit Care Med 2003; 168: 706-713.

5 Orozco-Levi M, Lloreta J, Minguella J, Serrano S, Broquetas JM, Gea J. Injury of the human diaphragm associated with exertion and chronic obstructive pulmonary disease. Am J Respir Crit Care Med 2001; 164: 1734-1739.

6 Orozco-Levi M, Gea J, Lloreta JL, et al. Subcellular adaptation of the human diaphragm in chronic obstructive pulmonary disease. Eur Respir J 1999; 13: 371-378.

7 Mercadier JJ, Schwartz K, Schiaffino S, et al. Myosin heavy chain gene expression changes in the diaphragm of patients with chronic lung hyperinflation. Am J Physiol 1998; 274: L527-L534.

8 Ottenheijm CA, Heunks LM, Sieck GC, et al. Diaphragm dysfunction in chronic obstructive pulmonary disease. Am J Respir Crit Care Med 2005; 172: 200-205.

9 Ottenheijm CA, Heunks LM, Hafmans T, et al. Titin and diaphragm dysfunction in chronic obstructive pulmonary disease. Am J Respir Crit Care Med 2006; 173: 527-534.

10 Ottenheijm CA, Heunks LM, Li YP, et al. Activation of ubiquitin-proteasome pathway in the diaphragm in chronic obstructive pulmonary disease. Am J Respir Crit Care Med 2006; 174: 997-1002.

11 Lindahl U, Kusche-Gullberg M, Kjellen L. Regulated diversity of heparan sulphate. J Biol Chem 1998; 273: 24979-24982.

12 Couchman JR. Syndecans: proteoglycan regulators of cellsurface microdomains? Nat Rev Mol Cell Biol 2003; 4: 926-937.

13 Iozzo RV. Basement membrane proteoglycans: from cellar to ceiling. Nat Rev Mol Cell Biol 2005; 6: 646-656.

14 Jenniskens GJ, Veerkamp JH, Van Kuppevelt TH. Heparan sulphates in skeletal muscle development and physiology. J Cell Physiol 2006; 206: 283-294.

15 Habuchi H, Suzuki S, Saito T, et al. Structure of a heparan sulphate oligosaccharide that binds to basic fibroblast growth factor. Biochem J 1992; 285: 805-813.

16 Turnbull JE, Fernig DG, Ke Y, Wilkinson MC, Gallagher JT. Identification of the basic fibroblast growth factor binding sequence in fibroblast heparan sulphate. J Biol Chem 1992; 267: 10337-10341.

17 Lyon M, Deakin JA, Mizuno K, Nakamura T, Gallagher JT. Interaction of hepatocyte growth factor with heparan sulphate. Elucidation of the major heparan sulphate structural determinants. J Biol Chem 1994; 269: 11216-11223.

18 Arai T, Parker A, Busby W Jr, Clemmons DR. Heparin, heparan sulphate, and dermatan sulphate regulate formation of the insulin-like growth factor-I and insulin-like growth factor-binding protein complexes. J Biol Chem 1994; 269: 20388-20393.

19 Feyzi E, Lustig F, Fager G, Spillmann D, Lindahl U, Salmivirta M. Characterization of heparin and heparan sulphate domains binding to the long splice variant of platelet-derived growth factor A chain. J Biol Chem 1997; 272: 5518-5524.

20 McCaffrey TA, Falcone DJ, Du B. Transforming growth factor- $\beta 1$ is a heparin-binding protein: identification of putative heparin-binding regions and isolation of heparins with varying affinity for TGF- $\beta 1$. J Cell Physiol 1992; 152: 430-440.

21 Bernfield M, Gotte M, Park PW, et al. Functions of cell surface heparan sulphate proteoglycans. Annu Rev Biochem 1999; 68: 729-777.

22 Crisona NJ, Allen KD, Strohman RC. Muscle satellite cells from dystrophic $(\mathrm{mdx})$ mice have elevated levels of heparan sulphate proteoglycan receptors for fibroblast growth factor. J Muscle Res Cell Motil 1998; 19: 43-51.

23 McFarland DC, Liu X, Velleman SG, Zeng C, Coy CS, Pesall JE. Variation in fibroblast growth factor response and heparan sulphate proteoglycan production in satellite cell populations. Comp Biochem Physiol C Toxicol Pharmacol 2003; 134: 341-351.

24 Casar JC, Cabello-Verrugio C, Olguin H, Aldunate R, Inestrosa NC, Brandan E. Heparan sulphate proteoglycans are increased during skeletal muscle regeneration: requirement of syndecan-3 for successful fiber formation. J Cell Sci 2004; 117: 73-84.

25 Van Kuppevelt TH, Dennissen MA, van Venrooij WJ, Hoet RM, Veerkamp JH. Generation and application of typespecific anti-heparan sulphate antibodies using phage display technology. Further evidence for heparan sulphate heterogeneity in the kidney. J Biol Chem 1998; 273: 12960-12966.

26 Van Kuppevelt TH, Jenniskens GJ, Veerkamp JH, ten Dam GB, Dennissen MA. Phage display technology to obtain antiheparan sulphate antibodies. Methods Mol Biol 2001; 171: 519-534.

27 Jenniskens GJ, Oosterhof A, Brandwijk R, Veerkamp JH, Van Kuppevelt TH. Heparan sulphate heterogeneity in skeletal muscle basal lamina: demonstration by phage display-derived antibodies. J Neurosci 2000; 20: 4099-4111.

28 Smetsers TF, van de Westerlo EM, ten Dam GB, et al. Human single-chain antibodies reactive with native chondroitin sulfate detect chondroitin sulfate alterations in melanoma and psoriasis. J Invest Dermatol 2004; 122: 707-716.

29 Lensen JF, Wijnhoven TJ, Kuik LH, et al. Selection and characterization of a unique phage display-derived antibody against dermatan sulfate. Matrix Biol 2006; 25: 457-461.

30 Lensen JF, Rops AL, Wijnhoven TJ, et al. Localization and functional characterization of glycosaminoglycan domains in the normal human kidney as revealed by phage displayderived single chain antibodies. J Am Soc Nephrol 2005; 16 : 1279-1288. 
31 Celli BR, MacNee W. Standards for the diagnosis and treatment of patients with COPD: a summary of the ATS/ ERS position paper. Eur Respir J 2004; 23: 932-946.

32 Pauwels RA, Buist AS, Calverley PM, Jenkins CR, Hurd SS; GOLD Scientific Committee, Global strategy for the diagnosis, management, and prevention of chronic obstructive pulmonary disease. NHLBI/WHO Global Initiative for Chronic Obstructive Lung Disease (GOLD) Workshop summary. Am J Respir Crit Care Med 2001; 163: 1256-1276.

33 Charge SB, Rudnicki MA. Cellular and molecular regulation of muscle regeneration. Physiol Rev 2004; 84: 209-238.

34 Esko JD, Lindahl U. Molecular diversity of heparan sulphate. J Clin Invest 2001; 108: 169-173.

35 Conrad HE. Heparin-Binding Proteins. New York, Academic Press, 1998.

36 Jennische E, Ekberg S, Matejka GL. Expression of hepatocyte growth factor in growing and regenerating rat skeletal muscle. Am J Physiol 1993; 265: C122-C128.

37 Powell-Braxton L, Hollingshead P, Warburton C, et al. IGF$\mathrm{I}$ is required for normal embryonic growth in mice. Genes Dev 1993; 7: 2609-2617.

38 MacGowan NA, Evans KG, Road JD, Reid WD. Diaphragm injury in individuals with airflow obstruction. Am J Respir Crit Care Med 2001; 163: 1654-1659.

39 Nguyen T, Shrager J, Kaiser L, et al. Developmental myosin heavy chains in the adult human diaphragm: coexpression patterns and effect of COPD. I Appl Physiol 2000; 88: 1446-1456.

40 Lewis MI, Horvitz GD, Clemmons DR, Fournier M. Role of IGF-I and IGF-binding proteins within diaphragm muscle in modulating the effects of nandrolone. Am J Physiol Endocrinol Metab 2002; 282: E483-E490.

41 Petrini S, Tessa A, Carrozzo R, et al. Human melanoma/ NG2 chondroitin sulphate proteoglycan is expressed in the sarcolemma of postnatal human skeletal myofibers. Abnormal expression in merosin-negative and Duchenne muscular dystrophies. Mol Cell Neurosci 2003; 23: 219-231.

42 Barbosa I, Morin C, Garcia S, et al. A synthetic glycosaminoglycan mimetic (RGTA) modifies natural glycosaminoglycan species during myogenesis. J Cell Sci 2005; 118: 253-264.

43 Gautron J, Kedzia C, Husmann I, Barritault D. [Acceleration of the regeneration of skeletal muscles in adult rats by dextran derivatives.]. C R Acad Sci III 1995; 318: 671-676.

44 Zimowska M, Szczepankowska D, Streminska W, et al. Heparan sulphate mimetics modulate calpain activity during rat Soleus muscle regeneration. J Cell Physiol 2001; 188: 178-187.

45 Desgranges P, Barbaud C, Caruelle JP, Barritault D, Gautron J. A substituted dextran enhances muscle fiber survival and regeneration in ischemic and denervated rat EDL muscle. FASEB J 1999; 13: 761-766. 